\title{
Pavement Subgrade Soils Qualified with Gyratory Compaction
}

\author{
Antonia Athanasopoulou ${ }^{1}$, George Kollaros ${ }^{1}$ \\ ${ }^{I}$ (Department of Civil Engineering, Democritus University of Thrace, Greece)
}

\begin{abstract}
A parameter used to carry out the quality control of unbound compacted soil materials is the maximum dry unit weight obtained from a standard or modified Proctor test. Being unchanged over the last decades, these tests do not fully simulate the compaction in the field. Curves of modified Proctor compaction as well as those obtained from the gyratory compactor are presented. The controlled variables in the gyratory compactor were the vertical pressure, the gyration angle, and of course the number of gyrations. The compaction curves are more or less similar disregarding the rate of gyration and gyration angle. The dynamic compaction yielded better results compared to those obtained by the gyratory compactor. The difference between the two compaction modes was greater at low moistures. Three different moistures were used. In any case, the dynamic method led to higher dry density values. California Bearing Ratio specimens prepared with dynamic or gyratory compaction have lower values with an increase in moisture content and were generally greater in the case of dynamic compaction. Through continued research, a more standard technique could be received for soil testing with gyratory compaction.
\end{abstract}

Keywords: bearing capacity, gyratory compactor, Proctor, soil compaction

\section{INTRODUCTION}

Compaction is the process applied to densify soils by mechanical means. Compaction is considered as one of the most critical features in the construction of transportation infrastructure like roads, embankments, airfields etc. Since long time, engineers have wanted to acquire a new laboratory process for soil compaction [1]. The goal is to represent more accurately the modern field compaction conditions [2]. Up to these days, the compaction methods most commonly used are the Standard and Modified Proctor tests, which have remained relatively unchanged since the 1930s and 1950s, respectively. Technology progress has brought about advances in field compaction. On the other hand, the Proctor hammer is not necessarily representative of the usual field compaction motions and pressures (static, kneading or vibratory) [3]. The exclusive intend for the creation of Superpave Gyratory Compactor (SGC) in the decade of 1990 was to test hot mix asphalt. Many researchers have made the hypothesis that gyratory compactors may be used to compact soil materials in the laboratory $[4,5]$. In 2006, Browne [6] studied the feasibility of SGC use for soil compaction suggesting that this device closely represents in situ compaction. The procedure used by Browne was based on the guidance of the AASHTO T132 compaction method [7] for hot mix asphalt. Depending on the soil type and the moisture content, the most important parameters controlled by the SGC were the number of gyrations, as well as the confinement pressure. In general, when the confinement pressure increases, the compaction dry unit weights for fine-grained soils also increase [8]. It has been shown that increasing the number of gyrations would lead to increased compaction dry unit weights for non-cohesive, granular soils [9]. Panko et al. (2011) [10] used the SGC trying to find an acceptable alternative to standard ASTM compacting methods for the moisture-density relation of pavement subbase or base materials and found that increased number of gyrations yielded high densification of unbound materials. A similar effort to access subbase materials in airfield runway has been undertaken at the National Airport Pavement Test Facility of the Federal Aviation Administration (FAA) [11]. When the modified Proctor test for the determination of the optimal moisture content (OMC) and maximum dry density (MDD) of soils is used, vertical work is exerted on the soil sample. On the contrary, when the SGC is being used to compact granular soils, shear work, due to the gyration angle, is applied to the soil complementing the vertical work.

Pérez and colleagues in 2013 [12] have evaluated the method of soil compaction using gyratory compactor instead of Proctor compaction for three different soils (classified as sand SM, silt ML and clay CH according to Unified Classification System). At least for the three speeds and two angles of gyration tested, the resulting compaction curves were independent of these variables. Nevertheless, it had been found that a series of variables can be controlled in the gyratory compactor making it possible to obtain the standard compaction curve. Many different reasons could underlay the favorable use of gyratory compactors for soil compaction in the laboratory. First of all, these instruments are more accurate than impact hammers, have greater effectiveness against impact hammers, and its easier to repeat the testing conditions with gyratory compactors $[13,14,15]$. Flexible pavement systems experience moving traffic loads. The action of moving wheels which is transferred to the pavement structure can be simulated by the gyratory compactors which apply vertical loads and kneading action simultaneously [16]. Furthermore, the internal structure of specimens prepared with a gyratory compactor closer resembles that of actual soil material in road projects. In recent years, artificial neural networks have been 
used with great success for modeling almost every geotechnical engineering problem, the most complex ones. Based on this principle, a research has been conducted [17] to find compaction parameters from easily measured index properties of soils. A total of over 180 laboratory test data had been used for the development and verification of the prepared model. It has been shown that OMC and MDD prediction could be made with high accuracy using soil index parameters, such as Liquid Limit, Plastic Limit, Plasticity Index, \% fines, \% sand and $\%$ gravel, and specific gravity. The artificial neural networks approach is data driven and output parameters are determined using pairs of input-output data. A gyratory compactor has been added to the equipment of Highway Construction and Pavements Laboratory in Democritus University, Xanthi, Greece. Compaction curves using the modified Proctor compaction test as well as those obtained from the gyratory compactor are presented in the following sections. The controlled variables in the gyratory compactor were the vertical pressure, the gyration angle, and the number of gyrations. Bearing Ratio specimens were prepared both with dynamic and gyratory compaction and the results of their testing were compared for the two methods.

\section{MATERIALS AND METHODS}

The method of gyratory compaction using SGC achieves the compactability assessment of specimens by the application of a $600 \mathrm{kPa} \pm 18 \mathrm{kPa}$ vertical stress via platens to a mass of asphaltic mixture inside a mold with a diameter of $100 \mathrm{~mm}$ or $150 \mathrm{~mm}$ (commonly used when testing asphalt). Whilst the machine keeps the platens horizontal and parallel to each other, the mold is gyrated along its longitudinal axis at a fixed angle $\left(1.25^{\circ} \pm 0.2^{\circ}\right)$ relative to the vertical axis. During the test, the height of the specimen is measured automatically and the mixture density and void content are calculated. Compaction data is displayed in real time. The compaction options are either to proceed for a prescribed number of gyrations or until a given mixture density or void content is achieved. Five sampling sites in Xanthi, Northern Greece, have been chosen in order to take soil quantities for laboratory testing. The sites are scattered within an area of a radius of about 20 kilometers so as to be representative of different prevailing conditions. Soil samples were assigned the names S1 to S5. A series of tests have been performed on the soil samples; the Atterberg limits determination, the methylene blue test, the sand equivalent test, as well as free swell tests and tests for the relationship between density and moisture (modified Proctor) were included. Using both the dynamic hammer compaction method and the gyratory compaction process, cylindrical specimens have been formed with the optimum moisture content and moisture contents under and over this value in order to evaluate the corresponding maximum dry densities. Gyratory specimens were compacted by introducing the material all at once inside the mould. The California Bearing Ratio (CBR) tests on the samples in non saturated conditions determined the bearing capacity of these materials to be used as subgrade in highway construction. The grain size distribution of the soils tested is given in Fig. 1. All soil samples were characterized as A-2-6 according to the AASHTO classification of soils.

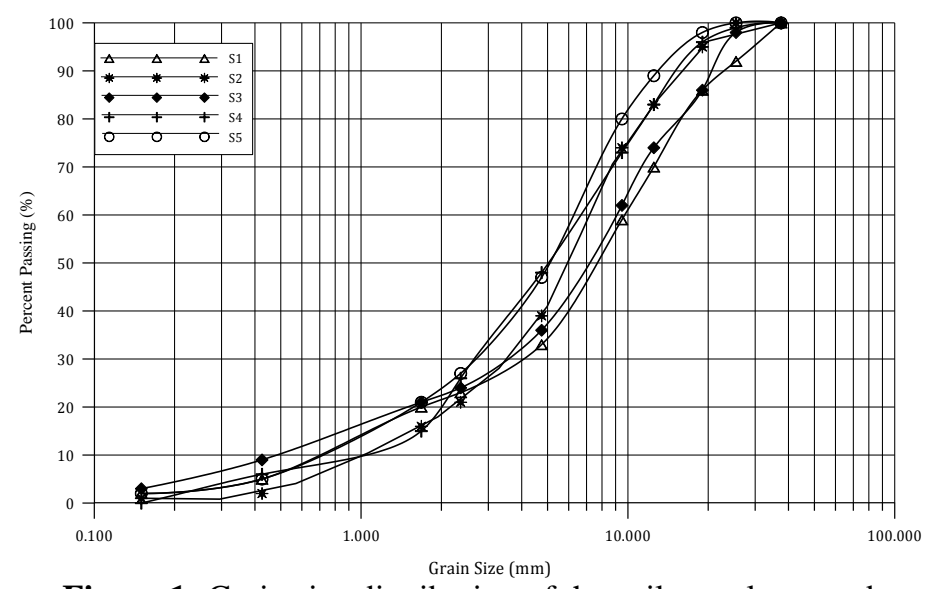

Figure 1: Grain size distribution of the soil samples tested

\section{RESULTS}

In Table 1, the results of the different tests performed in the laboratory are listed for the five soils under investigation. It must be noted that all soils were sampled at the same time period. So, their natural moisture is indicative of the season of the year (spring). Due to the distance between the sampling sites moistures ranged between $6.40 \%$ and $20.08 \%$ for samples $\mathrm{S} 5$ and $\mathrm{S} 2$ respectively. 
Table 1: Properties of the five soil specimens subjected to laboratory tests

\begin{tabular}{|l|l|l|l|l|l|}
\hline & S1 & S2 & S3 & S4 & S5 \\
\hline Natural Moisture (\%) & 11.96 & 20.08 & 9.53 & 10.21 & 6.40 \\
\hline Liquid Limit (\%) & 31 & 38 & 35 & 35 & 37 \\
\hline Plastic Limit (\%) & 14 & 10 & 23 & 17 & 14 \\
\hline Plasticity Index (\%) & 17 & 28 & 12 & 18 & 23 \\
\hline Linear Shrinkage (\%) & 8.57 & 13.57 & 9.35 & 10 & 12.19 \\
\hline Methylene Blue (mg/g) & 15.59 & 17.42 & 13.98 & 9.14 & 15.59 \\
\hline Free Swell (\%) & 35 & 51 & 43 & 37 & 57 \\
\hline Sand Equivalent (\%) & 24 & 10 & 17 & 11 & 8 \\
\hline AASHTO Classification & A-2-6 & A-2-6 & A-2-6 & A-2-6 & A-2-6 \\
\hline
\end{tabular}

The greater value for the Linear Shrinkage (LS) measured has been found for the soil sample S2 as $13.57 \%$ along with the maximum Liquid Limit (LL) (38) which is consistent with the nature of the soil. On the other hand, the lower LS and LL values were obtained for the S1 sample (8.57\% and 31, respectively). The S3 sample presented the maximum and the $\mathrm{S} 2$ sample the minimum plastic limit (23 and 10 respectively).Referring to the free swell of the soils, it is observed that it ranged between 35 (soil sample 1) and 57 (soil sample S5). The methylene blue test is based on the import in successive increasing portions of methylene blue solution on a suspension of the material to be examined until saturation is achieved. The methylene blue supplements the sand equivalent (SE) and Atterberg limits tests in determining the existence of particle with clay dimensions. The values of methylene blue determined in the laboratory are quite similar in magnitude with the higher one corresponding to S2 sample. The SE values for S1 and S5 samples are the highest and the lowest of the five (24 and 8 , respectively).Soil samples have been compacted both dynamically and with the gyratory compactor. Dynamic compaction is a well known technique for the improvement of soils since it densifies them using a drop weight. Each gyroscopic specimen has been compacted using a specified speed of 30 rounds per minute (rpm) and an angle of 20.00 milliradians (mrad) or equivalently 1.15 degrees. In order to get comparable results with the CBR method, a limitation had been posed to the height of gyratory specimens (117.6 mm); in such a way the exactly same height and weight was determined for the specimens of the two methods. The height of the specimens was reduced initially with a higher rate after each rotation cycle. In Table 2 , the values of optimum moisture content and maximum dry density, along with those of CBR tests, are shown. The OMC values ranged from $10.39 \%$ (S1) to $19.1 \%$ (S5), while MDD found in the region of $1741.79 \mathrm{~kg} / \mathrm{m}^{3}$ (S4) to $1987.50 \mathrm{~kg} / \mathrm{m}^{3}(\mathrm{~S} 1)$. The values of CBR have been obtained using the optimum moisture content found through the modified Proctor procedure (ASTM D1557-12).

Table 2: Moisture, density (modified Proctor) and CBR values of soil specimens

\begin{tabular}{|c|c|c|c|}
\hline Soil Sample & $\begin{array}{c}\text { Optimum Moisture Content } \\
(\%)\end{array}$ & $\begin{array}{c}\text { Maximum Dry Density } \\
\left(\mathrm{kg} / \mathrm{m}^{3}\right)\end{array}$ & $\begin{array}{c}\text { CBR } \\
(\%)\end{array}$ \\
\hline S1 & 10.39 & 1987.50 & 18 \\
\hline S2 & 15.81 & 1801.13 & 7 \\
\hline S3 & 15.66 & 1986.36 & 8 \\
\hline S4 & 17.20 & 1741.79 & 13 \\
\hline S5 & 19.10 & 1840.00 & 10 \\
\hline
\end{tabular}

The S1 specimen, compacted dynamically at $10.03 \%$ moisture content, has yielded the maximum dry laboratory density $\left(2024.95 \mathrm{~kg} / \mathrm{m}^{3}\right)$. The S3 specimen compacted dynamically at $21.55 \%$ moisture content yielded the lower dry laboratory density $\left(1629.22 \mathrm{~kg} / \mathrm{m}^{3}\right)$. In the case of gyroscopically compacted specimens, the highest and lowest densities were furnished by the S4 and S3 specimens, respectively when they were compacted using $13.96 \%$ and $21.22 \%$ moisture contents. The dry density values in these cases were 1889.54 $\mathrm{kg} / \mathrm{m}^{3}$ and $861.33 \mathrm{~kg} / \mathrm{m}^{3}$, respectively. As the moisture at which the specimen has been compacted increases, the shear is reduced. The higher shear $(443 \mathrm{KN} / \mathrm{m} 2)$ was observed in the $\mathrm{S} 2$ specimen was compacted gyroscopically at $14 \%$ moisture. On the contrary, the smaller shear $\left(35 \mathrm{KN} / \mathrm{m}^{2}\right)$ was observed in S3 specimen compacted gyroscopically at $20 \%$ moisture. Finally, the density of the sample specimens increases at the end of the rotation cycles. More specifically, the higher density $\left(2211 \mathrm{~kg} / \mathrm{m}^{3}\right)$ has been observed in the S3 specimen compacted gyroscopically at $14 \%$ moisture, while the lower density $\left(1989 \mathrm{~kg} / \mathrm{m}^{3}\right)$ has been observed in the S5 specimen compacted gyroscopically at $14 \%$ moisture. It is obvious that when the dynamic compaction was used the result obtained was sensibly better compared to those yielded by the gyratory compactor. More specifically, at the low moistures, the difference is greater between the two compaction modes. Also, the dynamic method leads to higher dry density values for all specimens tested in all three different moistures used. 
The results of the Proctor tests on the soil samples are presented in Fig. 2.

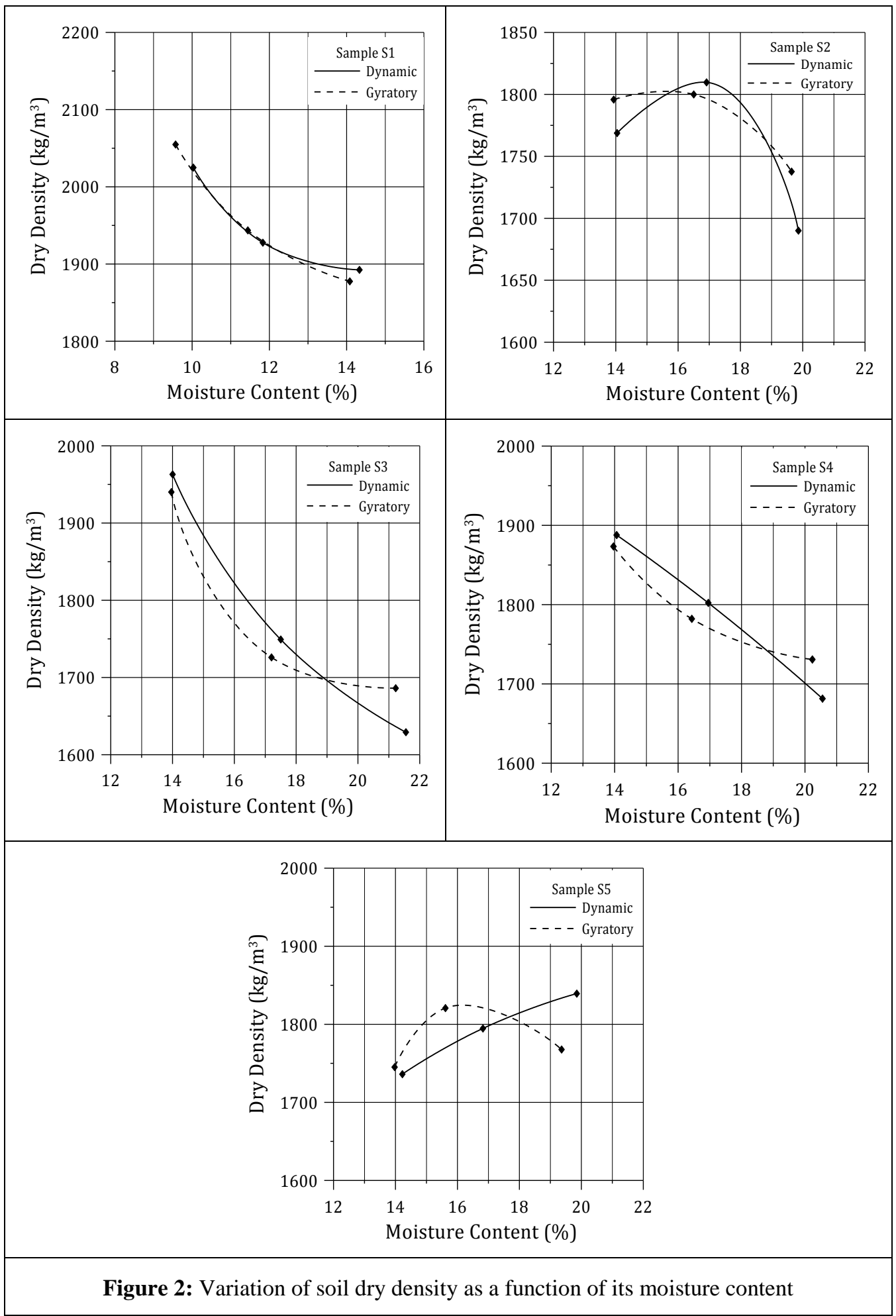

Comparing the behavior under dynamic and gyratory compaction there are no consistent trends. In general the densities obtained with the gyratory compaction are smaller than those with the dynamic process, with the exception of Sample 5 in the lower moistures. Sample 4 appears to buckle forming a sag curve when dynamically compacted. Sample S2 yielded convex shaped curves for both compaction modes. The moisture content of the soils, as shown in Fig. 2, varied in a relatively narrow range of values. This could be expected since the sampling was made in a wide, but uniform in type, soil area. 
Table 3 depicts the relationship developed between the moisture in the specimens and the recorded CBR values. Two different values are shown referring to the way the specimen has been compacted (dynamically or with the use of gyratory compactor).

Table 3: Variation of California bearing ratio as a function of moisture content

\begin{tabular}{|l|l|l|l|l|}
\hline \multirow{3}{*}{ Soil Sample } & \multicolumn{2}{|l|}{ Dynamic Compaction } & \multicolumn{2}{l|}{ Gyratory Compaction } \\
\cline { 2 - 5 } & Moisture (\%) & CBR (\%) & Moisture (\%) & CBR (\%) \\
\hline \multirow{4}{*}{ S1 } & 10,03 & 18 & 9,57 & 25 \\
\cline { 2 - 5 } & 11,83 & 9 & 11,44 & 11 \\
\cline { 2 - 5 } & 14,33 & 3 & 14,08 & 4 \\
\hline \multirow{3}{*}{ S2 } & 14,04 & 33 & 13,93 & 30 \\
\cline { 2 - 5 } & 16,91 & 20 & 16,5 & 10 \\
\cline { 2 - 5 } & 19,86 & 4 & 19,65 & 3 \\
\hline \multirow{3}{*}{ S3 } & 14,00 & 10 & 13,97 & 9 \\
\cline { 2 - 5 } & 17,50 & 2 & 17,20 & 3 \\
\cline { 2 - 5 } & 21,55 & 1 & 21,22 & 2 \\
\hline \multirow{3}{*}{ S4 } & 14,06 & 24 & 13,96 & 15 \\
\cline { 2 - 5 } & 16,95 & 7 & 16,43 & 7 \\
\cline { 2 - 5 } & 20,55 & 2 & 20,22 & 2 \\
\hline \multirow{3}{*}{ S5 } & 14,22 & 57 & 13,97 & 25 \\
\cline { 2 - 5 } & 16,82 & 20 & 15,61 & 11 \\
\cline { 2 - 5 } & 19,85 & 10 & 19,36 & 4 \\
\hline
\end{tabular}

\section{CONCLUSION}

It is important to study the behavior of compacted soils, since they are involved in many civil engineering construction projects. The laboratory density can control the quality of this behavior. Proctor tests have served this determination for many years. Soil dry unit weights can be a practical method for the analysis and further comparison of gyratory results to traditional compaction test results. In all five soils tested in this study, the modified Proctor dry densities surpassed those from the gyratory compaction. Despite this observation, gyratory compaction could be considered as a feasible means of laboratory compaction. More evidence is needed based on different soil types, and other variables involved in the procedure like the number of gyrations, the confinement pressure the angle of rotation etc. It is suggested the highest number of gyrations to be used to allow the maximum of soil densification to be achieved. The CBR values proved to be a valuable assistance for the judgment of the compaction method to be used bearing in mind the drawbacks of both the Proctor and gyratory compaction methods. California Bearing Ratio specimens prepared with dynamic or gyratory compaction have lower values with an increase in moisture contents and were generally greater in the case of dynamic compaction. The difference was greater at moistures lower than the optimum one. It is suggested artificial neural networks be used for the prediction of soil OMC and MDD values. Because such an analysis could be easily executed based on simple soil index parameters, it is thought to be a useful tool for engineers. In order to develop a standardized protocol for gyratory compaction of soils, continued research is necessary. The outcome of such research efforts provide engineers with a more thorough understanding of freedraining soils. Future studies may also lead to a better understanding of gyratory compaction mechanism by comparing dry unit weights or energies of gyratory compaction to field compaction instead making this comparison with existing laboratory compaction procedures.

\section{REFERENCES}

[1] A. Vinay, and M.V. Hemanth Yadav, Study and comparison of soil compaction between laboratory and field to simulate field compaction for rural roads, International Research Journal of Engineering and Technology (IRJET), 2(4), 2015, 2086-2092.

[2] R. Mokwa, E. Cuelho, and M. Browne, Laboratory testing of soil using the Superpave gyratory compactor, Transportation Research Board $87^{\text {th }}$ Annual Meeting Proceedings, Committee AFS10, Transportation Earthworks, Advanced Technologies for Accelerated Earthwork Construction and Performance Monitoring. January 14-17, Washington, DC, 2008.

[3] V. Drnevich, A. Evans, and A. Prochaska, A study of effective soil compaction control of granular soils, Final Report FHWA/IN/JTRP-2007/12, 2007.

[4] W.V. Ping, M. Leonard, and Z. Yang, Evaluation of laboratory compaction techniques for simulating field soil compaction (Phase I). Research Report No.: FL/DOT/RMC/BB-890(F) Project No.: 6120-549-39 Department of Civil \& Environmental Engineering Florida A\&M University, Tallahassee, FL 32310, 2003.

[5] W.V. Ping, M. Leonard, and Z. Yang, Evaluation of laboratory compaction techniques for simulating field soil compaction (phase II). Research Report No.: FL/DOT/RMC/BB-890(F) FSU Project No.: 6120-549-39 Department 
of Civil \& Environmental Engineering Florida A\&M University - Florida State University, College of Engineering, Tallahassee, FL 32310, 2003.

[6] M.J. Browne, Feasibility of using a gyratory compactor to determine compaction characteristics of soil, master's thesis, Montana State University - Bozeman, MT, 2006.

[7] American Association of State and Highway Transportation Officials (AASHTO), AASHTO T 312-15 Standard method of test for preparing and determining the density of asphalt mixture specimens by means of the Superpave gyratory compactor, 2015.

[8] A.G. Altschaeffl, and C.W. Jr. Lovell, Compaction variables and compaction specification, Proc., $54^{\text {th }}$ Annual Road School, Engineering Bulletin, Extension Series No. 131, Purdue University, 1969, 116-133.

[9] D.J. White, P.K.R. Vennapusa, and M.J. Thompson. Field validation of intelligent compaction monitoring technology for unbound materials. Partnership for Geotechnical Advancement (PGA), Center for Transportation Research and Education (CTRE) Iowa State University, 2007.

[10] M. Panko, J. Stevenson, C. Hurt, S. Coffey, K. McGarvey, Y.A. Mehta, and B. Sukumaran, Compaction of granular soils using Superpave gyratory compactor at higher confining pressures. Transportation Research Board $90^{\text {th }}$ Annual Meeting, Washington, D.C., Jan 23-27, Paper Number 11-3772, 2011.

[11] C.E. Cary, C. Kumpel, A. Bagriacik, R. Cohen, J. Clark, and B. Sukumaran, Assessment of field compaction of subbase material during construction and trafficking of heavy aircraft using the Superpave Gyratory Compactor, Proc. FAA Worldwide Airport Technology Transfer Conf., Galloway, New Jersey, USA, August 2014.

[12] N. Pérez, P. Garnica, I. Mendoza, and M.A. Reyes, Behavior of fine-grained soils compacted with high shear stresses. Proc. of the $18^{\text {th }}$ International Conf. on Soil Mechanics and Geotechnical Engineering, Paris, 2013, 407-410.

[13] T. Harman, J.R. Bukowski, F. Moutier, G. Huber, and R. McGennis, The history and future challenges of gyratory compaction 1939 to 2001. Transportation Research Record, 1789(1), 2002, 200-207.

[14] G. Cerni, and S. Camilli, Comparative analysis of gyratory and Proctor compaction processes of unbound granular materials, Road Materials and Pavement Design, 12(2), 2011, 397-421.

[15] J. Chen, B. Huang, F. Chen, and X. Shu, Application of discrete element method to Superpave gyratory compaction, Road Materials and Pavement Design, 13(3), 2012, 480-500.

[16] C. Li, D.J. White, and P. Vennapusa, Moisture-density-strength-energy relationships for gyratory compacted geomaterials, ASTM Geotechnical Testing Journal, 38(4), 2015, 461-473.

[17] J. Jayan, and N. Sankar, Prediction of compaction parameters of soils using artificial neural networks, Asian Journal of Engineering and Technology, 3(4), Special issue for ICETTAS'15, 2015, 368-375. 